\title{
CALCIFIED AORTIC VALVE CLINICAL AND RADIOLOGICAL FEATURES
}

BY

\author{
C. E. DAVIES AND R. E. STEINER \\ From The Royal Sheffield Infirmary and Hospital
}

Received October 22, 1948

The object of this paper is to suggest that a diagnosis of calcified aortic valve can justifiably be made more often than is the current practice, and that the lesion can be convincingly demonstrated and permanently recorded by a special radiological technique not hitherto described.

Rayger described the first recorded case of calcified aortic valve in 1697: he performed an autopsy, and sent one of the calcified cusps to Bonet, who described it in a publication dated 1700. A few years later Cowper (1706) described a man of forty with dyspnœa, angina, faintness and petrifaction of the aortic valve - " the valves of the Great Artery were Petrify'd insomuch that they could not approach each other." Further cases were reported by Vieussens (1715), Chevers (1842), Lloyd (1846), and Peacock (1868). Lannaec (1829) gives an excellent clinical description. The earliest extensive pathological account is that of Hasse (1846).

In more modern times, calcified aortic valve was neglected until 1931, when Christian reported a series of 22 cases, and attempted to lay down clinical criteria for the diagnosis. Interest was further aroused by the paper of Sosman and Wosika (1933) on radiological demonstration of valvular calcification, and there have been numerous American papers on all aspects of the subject up to the present time.

The English papers on the subject, however, are extremely scanty. Bennett (1930) reported a single case, and Gibbs (1935) described the pathology. Campbell and Shackle (1932) give the lesion passing mention in a general survey of aortic disease. The fullest account written in this country was that of Campbell (1937).

Frequency of the lesion. Hall and Ichioka (1940) found 31 cases of calcified aortic valve in 4000 autopsies: Dry and Willius (1939) found 23 cases in 2616 consecutive autopsies, and they further pointed out that calcified aortic valve constitutes 18 per cent of all healed valvular defects. The highest incidence of the lesion was that reported by Sophian (1945) who found 31 cases in 500 consecutive autopsies at the U.S. Marine Hospital. He attributed the high incidence of the lesion in his cases to age, sex, and occupation. Thus it appears that, although the available figures show a fairly wide range of variation, the lesion is undoubtedly quite common.

While discussing the incidence of the lesion, it is interesting to note how infrequently aortic stenosis occurs without calcification of the valve cusps. In Christian's series (1931) of 22 cases there was calcification in all but one; Dry and Willius (1939) reported 116 cases that came to necropsy, in all of which calcification was found, and 122 cases diagnosed clinically with radiologically demonstrable calcification. This shows that calcification occurs early in aortic stenosis and is almost always present by the time of death or diagnosis.

Unfortunately there are few figures available to show how frequently calcified aortic valve is diagnosed in life. Blackford and Bryan (1936) found less than 50 reported cases, that had been diagnosed in life, up to 1936. Berk and Dinnerstein (1938) reported 16 cases, of which only 5 were diagnosed in life, while Reich (1945) reported 22 cases, of which 11 were diagnosed. The later series show a much greater frequency of diagnosis than those prior to 1932: e.g. Margolis et al. (1931) reported 42 cases, of which only 2 were correctly diagnosed in life.

The Material for this Study

This paper describes 14 patients suffering from " pure" calcified aortic valve, in whom the lesion was suspected clinically and proved on radiological grounds. The table records the main facts concerning the patients.

Of the 14 patients, 12 were men and 2 women. Their ages ranged from 27 to 71 , the average being a little over 50 . Only 4 of the patients gave a 
TABLE I

Analysis of fourteen Cases of Calcified Aortic Valve

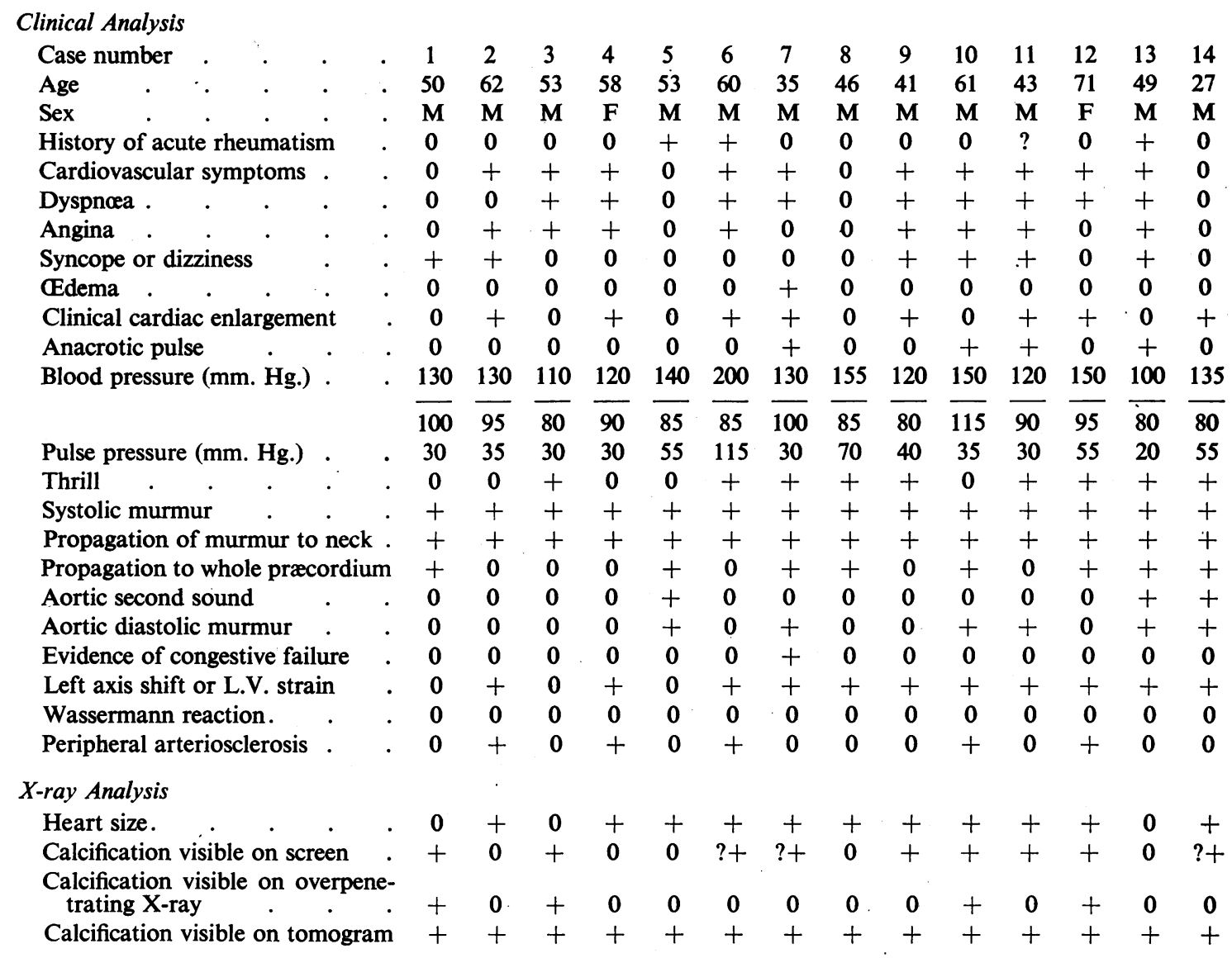

history of acute rheumatism, and in one of these it was doubtful. None of the patients gave a history of syphilis, and the Wassermann reaction was negative in all cases.

The symptoms of which the patients complained varied. Four had no symptoms referable to the cardiovascular system: of the other 10,9 complained of dyspnœa, 8 of angina pectoris, 6 of syncope or dizziness, and 1 of œedema. One man complained of loss of memory and of the power of concentration.

The physical findings were as follows: clinical evidence of cardiac enlargement was present in 8 patients; peripheral arteriosclerosis was found in 5 , and the pulse was thought to be anacrotic in 4 . The blood pressure was not characteristic, but in general-the systolic pressure was rather low and the diastolic rather high, unless the former were modified by associated hypertension or the latter by aortic regurgitation. The pulse pressure ranged from
30 to $115 \mathrm{~mm}$. $\mathrm{Hg}$., the average being $45 \mathrm{~mm}$. (see Table). In 9 of the patients there was a basal systolic thrill, and in all 14 a basal systolic murmur. The basal murmur was maximal in the second right intercostal space and was propagated to the root of the neck in all cases: in 8 of the patients the murmur was audible over the whole præcordium. The aortic second sound was audible in only 3 of the cases. There was an aortic diastolic murmur in 6 cases: but the presence of such a murmur did not bear any significant relationship to the height of the pulse pressure (see Table). Electrocardiography proved of no assistance in diagnosis and showed no characteristic features: 11 patients showed evidence of left axis deviation or left ventricular strain, and of these one showed left bundle branch block, one $2: 1 \mathrm{~A}-\mathrm{V}$ block and one the typical changes of anterior coronary occlusion. The cardiographs of the 3 remaining patients showed no abnormality. 
Ten of the patients have been followed up for periods up to two years. One died of congestive cardiac failure soon after admission, and 3 died suddenly within a few months of discharge from hospital: of the other 6 patients with whom contact has been maintained, one has developed severe dyspnœa and angina pectoris; the other 5 have remained unchanged.

\section{Etiology}

The ætiology of this condition is uncertain, and this investigation adds nothing to our knowledge of the subject. There is no evidence that the lesion is due to a disturbance of calcium metabolism (Bramwell and King, 1942) to focal sepsis as suggested by Thalheimer (1922) or to syphilis (Christian, 1931; Margolis et al., 1931; Grant, 1933). Libman (1913) and Perry (1936) observed that subacute bacterial endocarditis may heal by calcification, and Cohen et al. (1940) described one case of calcified aortic valve that showed healed aneurysms of the hepatic artery with renal and splenic infarcts. But, in general, there is no history in these patients suggestive of bacterial endocarditis.

The two views most commonly held regarding the ætiology are that it is a form of atherosclerosis (Monckeberg, 1904; Sohval and Gross, 1936), or that it is an unusual manifestation of rheumatic carditis (Cabot, 1926; Karsner and Koletsky, 1940 and 1947; Hall and Ichioka, 1940). Allbutt (1898) first pointed out the low incidence of atheroma of the aorta in cases of calcified aortic valve, and this fact has been confirmed many times since (Clawson et al., 1926; Scherf, 1938); Dry and Willius (1939) make a further observation that coronary atheroma is usually in inverse proportion to the degree of aortic stenosis.

The incidence of a history of acute rheumatism or chorea in this condition is variable, the lowest incidence (4 per cent) being in the series of Friedwald and Ewing (1938), and the highest (56 per cent) in that of Cabot (1926). In the present series 4 patients (28 per cent) gave a history of acute rheumatism.

The sex distribution of the disease is remarkable, whatever the rtiology. In favour of a rheumatic origin it has been argued that chorea, which is predominantly a disease of women, is rarely followed by aortic valve disease (Contratto and Levine, 1937; Clawson et al., 1938), that rheumatic carditis is a less severe disease in men than in women, and that the mild attacks are most likely to pass undiagnosed, and to be followed by slowly progressive lesions of the aortic valve (Dry and Willius, 1939).

The age incidence is more suggestive of atheroma than of rheumatic valvular disease: but cases have been recorded in young persons, and the fact that the lesion is well tolerated may lead to its escaping detection.

Histological evidence has been of little value in elucidating the problem, chiefly because authorities disagree in regard to the criteria of what constitutes evidence of old rheumatic affection.

The only conclusion warranted by the evidence available is that some patients with calcified aortic valve have, in addition, rheumatic lesions in the mitral valve; that in many cases of calcified aortic valve, without mitral valve disease, there is a history of acute rheumatism; and that those patients without mitral disease or a history of acute rheumatism, have lesions in the aortic valve that are indistinguishable from those in the other two groups.

\section{Clinical Symptoms}

Age and sex. In general the disease is one of men past middle life (Fothergill, 1879). The average age varies in different series from 52 years (Contratto and Levine, 1937) to 60 years (Friedwald and Ewing, 1938). The youngest case on record was a boy of 12 (Gautier, 1860).

The predominance of males is very striking. With the exception of Margolis et al. (1931), in whose series only 21 per cent were males, most series show a male incidence of over 80 per cent. This feature of the disease is difficult to explain. The suggestion that the more arduous physical life of the male, subjects the aortic cusps to greater trauma is not convincing. It seems more likely that the explanation lies in a difference in the natural history of acute rheumatism in the sexes.

Symptoms. Trousseau (1870) commented on the disparity between the mildness of symptoms and the severity of this lesion as demonstrated at autopsy. In this present series 3 of the 14 patients had no symptoms referable to the cardiovascular system.

Dyspnoea. This was the commonest symptom, occurring in 11 of the 14 cases; 2 (Cases 4 and 7) complained of dyspnca at rest, the others only on exertion. None complained of nocturnal paroxysmal dyspnœa, which is remarkable in view of the burden thrown on the left ventricle by calcified aortic valve.

It is remarkable that the lesion may be of long duration and associated with gross cardiac enlargement without producing dyspnœa. This may possibly be explained by the slow development of the so-called " compensatory" hypertrophy of the left ventricle over a long period.

Angina pectoris. The occurrence of angina was recorded in 1706 by Cowper, whose patient " complained ... of pain about the heart" and by Morgagni (1769). The discomfort experienced is 
often atypical, conforming rather to the true etymology of the word: several of the patients (Cases 10, 11, and 13) denied retrosternal pain but complained of a choking sensation on exertion. One man (Case 3 ) complained of a " heavy " pain below the left nipple which was significantly related to exertion. In Cabot's series (1926), only 3 of the 9 patients with angina had typical distribution of pain. Levine (1945) also noted that the pain was often atypical, and that the history was elicited only by careful questioning.

Eight out of 14 patients in the present series (57 per cent) complained of anginal symptoms. The incidence of angina in other series varies from 7 per cent (Grant, 1933) to 60 per cent (Friedberg and Sohval, 1939). Case 4 had an attack clinically and cardiographically indistinguishable from coronary thrombosis; she did not die in hospital and no autopsy was obtained. Boas (1935) reports a patient with typical symptoms and electrocardiogram of coronary thrombosis, whose coronary arteries at autopsy were healthy; he suggests that the onset of left ventricular failure may simulate coronary thrombosis, as a result of a sudden fall in cardiac output, with reduced coronary flow.

The mechanism of angina of effort in this disease is not clear. There is rarely associated disease of the coronary arteries or their ostia (Boas, 1935; Reich, 1940; Contratto and Levine, 1937), nor can the occurrence of angina be related to aortic regurgitation. Although 3 of the 8 cases with angina had aortic diastolic murmurs, none had the peripheral manifestations of aortic regurgitation.

Friedberg and Sohval (1939) suggested that angina was due to the very high intraventricular pressure, which develops in systole with intense contraction of the ventricle, compressing the coronary vessels in a manner comparable to the blanching of the clenched fist. Levine (1945) made the ingenious suggestion that angina was due to the forcible ejection of blood into the aorta in systole, causing a suction action and leading to coronary emptying. But whatever the mechanism of angina may be in this condition, there is no doubt that calcified aortic valve is the valvular lesion above all others associated with that symptom, if luetic aortitis, which is not primarily a disease of the valve, be excluded.

Dizziness and syncope. Cowper's patient (1706) " complained of great faintness" and this appears to be one of the commonest and most disabling symptoms of calcified aortic valve. Contratto (1940) states that "dizziness and syncope help to distinguish aortic stenosis from mitral stenosis and aortic incompetence, in which these symptoms are very rare."
In the present series 5 patients complained of disturbances of consciousness varying from a transient loss of attention to complete loss of consciousness lasting for some minutes. Loss of consciousness was not accompanied by an aura, convulsions, or incontinence, and recovery was complete immediately, without disturbance of memory, speech, or motor power, and without paræsthesiæ or headache. Marvin and Sullivan (1935) and Scherf (1938), on the other hand, state that the attacks are sometimes epileptiform in character.

In some of our cases the attacks were related to exertion (Cases 1, 2, 9, and 11), a fact observed by Fothergill in 1879, but in others they occurred when the patient was at rest (Cases 10 and 13). Marvin and Sullivan (1935) related the syncopal attacks to exertion in all their 11 cases except 1 , in whom the attack was post-prandial.

Mechanisms of disturbances of consciousness. It seems indisputable that the ultimate cause of loss of consciousness is cerebral anæmia, but the mechanism is obscure. Smith (1931) attributed it to insufficient left ventricular output in exertion, through a narrow aortic orifice: But in some cases syncope occurs at rest, and the occurrence of syncope is very variable, the amount of exertion which produces syncope one day having no effect on another.

There is no evidence that Stokes-Adams attacks are responsible for syncope, as the electrocardiogram between attacks shows evidence of heart block $(2: 1)$ in one case only (Case 11): this patient suffered from giddiness only and did not lose consciousness. Marvin and Sullivan (1935) induced an attack of syncope by exertion in one of their patients, and took continuous cardiographic tracings. At the onset of unconsciousness the heart rate was slow (50 a minute) and regular; the tracing showed nodal rhythm and marked depression of the origin of T II. A few seconds later ventricular premature beats appeared followed by simple paroxysmal tachycardia at a rate of 200 a minute. There were frequent changes in the position of the pacemaker after the subsidence of tachycardia. They concluded that loss of consciousness was due either to carotid sinus hypersensitivity, as described by Baker and Weiss (1935), or to diminished coronary flow during exertion, with a cardiac output so low as to induce unconsciousness. Carotid sinus hypersensitivity seems an improbable explanation. Contratto and Levine (1937) found that carotid sinus compression produced no effect in 19 patients with calcified aortic valve, who complained of disturbance of consciousness, and that observation has been borne out in the present series (Cases 10,11, and 13). The most acceptable explanation so far put forward 
is the occurrence of reduced coronary circulation with a marked reduction in cardiac output.

Mental changes. One patient (Case 10) complained of loss of memory and concentration sufficient to interfere with his normal activities.

\section{Physical Signs}

Blood pressure. The systolic blood pressure in the present series ranged from 100 to $200 \mathrm{~mm}$.: the diastolic from 80 to $115 \mathrm{~mm}$. $\mathrm{Hg}$. This bears out the findings of Contratto and Levine (1937).

The pulse and pulse pressure. Lewis (1934) states: "The outstanding feature of aortic stenosis is a small pulse, rising slowly to a delayed summit: the condition should never be diagnosed without this sign." Such a view is no longer tenable. McGinn and White (1934) found a plateau pulse in only 9 of their 236 cases. In the present series the pulse was thought to be characteristically anacrotic in 4 patients only (Cases 7, 10,11, and 13) in whom the blood pressures were $130 / 100,150 / 115,120 / 90$, and $100 / 80 \mathrm{~mm}$. $\mathrm{Hg}$. respectively. In 3 others (Cases 1, 2, and 4) in whom the pulse pressure was $30 \mathrm{~mm}$. or less, the pulse was thought not to be anacrotic. Pulse wave tracings, which might have been of value, were not obtained. In the present series the pulse pressure ranged from 30 to $115 \mathrm{~mm}$., the average being approximately $40 \mathrm{~mm}$. The pulse pressure presumably depends on the relative degrees of stenosis and regurgitation, and on the presence or absence of associated hypertension.

Heart size. Levine (1945) states that the heaviest hearts are those with aortic stenosis, although the largest silhouettes on X-ray examination are those with mitral stenosis. Christian (1931) found gross clinical cardiac enlargement in all his cases of calcified aortic valve, the average weight at autopsy being $680 \mathrm{~g}$. Most authors agree, with the exception of Scherf (1938), who states that "cardiac enlargement does not occur until the lesion has been present for years, often several decades;" and Cabot (1926) who found that the heart may be small, moderate, or large.

In the present series there was considerable enlargement of the heart in 8 of the 14 cases, slight enlargement in 3 , and none in the 3 others. In 8 cases the enlargement could be found on clinical examination.

Thrill. Nine of the 14 cases had a basal systolic thrill. Reported cases show great variation in the frequency of thrills in calcified aortic valve. Thus Christian (1931) regarded the thrill as an essential criterion, whereas in McGinn and White's series of 123 cases proved at autopsy, 25 per cent had a basal systolic thrill recorded. At the other extreme
Gibbs (1935) found a systolic thrill recorded in only 1 of 27 cases. It is apparent that the presence of a thrill depends on the intensity of the vibration in the heart, and on the distance of the palpating hand from the source, which may be increased by a thick chest wall or by the presence of emphysema. The low incidence of thrill in some of the series discussed from the viewpoint of pathology, such as that of Gibbs (1935), may be due to poor clinical records.

The heart sounds. Systolic murmur. Typically there is a loud systolic murmur, loudest at the base, which is conducted to the root of the neck, more on the right than on the left, and sometimes to the cardiac apex. In this series the murmur was harsh, and was propagated to the neck in all cases: in only 8 cases was it audible over the whole præcordium. In the series of McGinn and White (1934), all 113 cases had basal systolic murmurs, but the authors point out that in some of the cases which came to autopsy a harsh systolic murmur audible over the whole præcordium had, before death, been attributed to mitral valve disease. Cabot (1926) found that in 4 of his 28 cases, the systolic murmur was audible only at the apex.

The murmur is not characteristic (Scherf, 1938), for a similar murmur may be heard in aortic incompetence and in luetic aortitis. Nor is its propagation significant, for this depends on the intensity of the murmur (Contratto and Levine, 1937).

Diastolic murmur. Lewis (1934) requires an aortic diastolic murmur as well as an anacrotic pulse for the diagnosis of aortic stenosis, but that view is no longer held. In the present series an aortic diastolic murmur was heard in 6 out of 14 cases (42 per cent), and this inconstancy of the diastolic murmur is borne out in other series. Thus McGinn and White (1934) found diastolic murmurs in 53 per cent of cases, Contratto (1940) in 50 per cent, Cabot (1926) in 57 per cent, and Dry and Willius (1939) in 33 per cent.

Aortic second sound. On theoretical grounds, it seems unlikely that calcified aortic valve cusps could close with sufficient vigour to produce a second aortic sound. In the present series the second sound was inaudible in 11 cases and audible in 3 (Cases 5, 13, and 14), in whom it was of normal intensity. Contratto and Levine (1937) suggest that the audible second sound is really a pulmonary second sound. Scherf (1938) regards a weak or absent second aortic sound as helpful in distinguishing the murmur of calcified aortic valve from that of luetic aortitis and atheroma of the aorta, in which the sound is normal or accentuated. It may be said that whereas the absence of the aortic second 


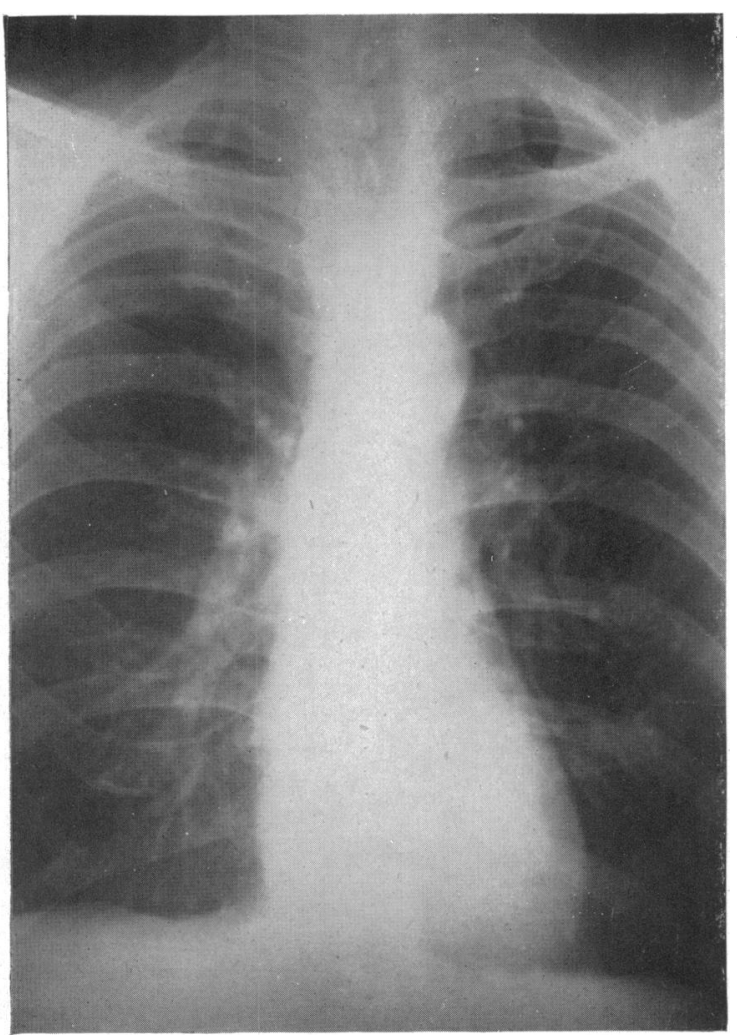

FIG. 1.-Case 1. Teleradiograph showing normal heart size and rounding of left cardiac contour, indicating left ventricular hypertrophy.

sound favours the diagnosis, its presence does not exclude it.

Evidence of congestive cardiac failure. In the present series one patient only (Case 7) presented with signs of congestive heart failure. Other authors have found the incidence much higher; for example, 26 of Cabot's 28 cases presented with œdema.

Disturbances of conduction. There have been many reports of disturbances of conduction in this condition. Cowper's case (1706) had "an intermission of one stroke in three of the pulse," and Parkes-Weber (1897) and Allbutt (1898) described cases with heart block. There have been numerous electrocardiographic reports and an extensive survey by Dry and Willius (1939). The electrocardiogram is frequently normal. The abnormalities commonly found are left axis shift, $T$ wave inversion, $\mathrm{A}-\mathrm{V}$ block which may vary in degree in the same patient (Boas, 1935), bundle branch block, smaller degrees of intraventricular block, and, very

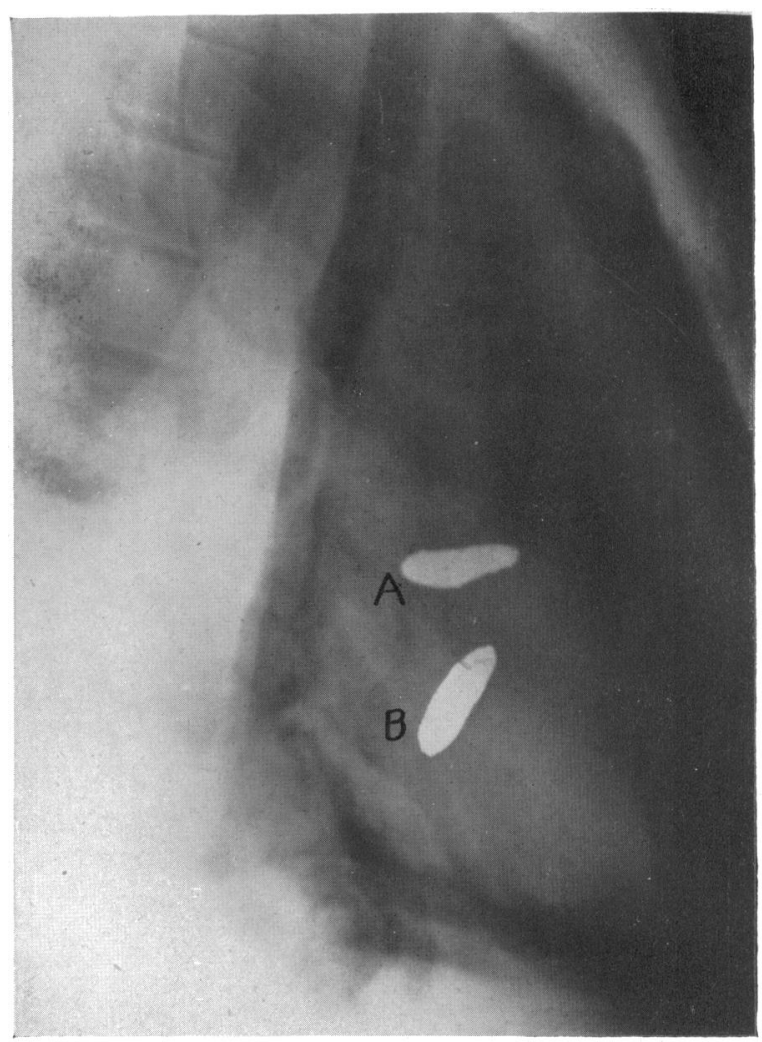

FIG. 2.-Oblique radiograph of the heart in the cadaver. A. represents the shadow of a lead strip in the aortic valve area.

B. represents the shadow of a lead strip in the mitral valve area.

rarely, auricular fibrillation (Contratto and Levine, 1937).

Heart block has been attributed to invasion of the conducting tissue by an extension of calcification from the valve (Boas, 1935 and East, 1932). This may be so in some cases, but it would not account for intraventricular disturbances, nor for variable disturbances. Diminished coronary flow is probably the causative factor in most cases.

\section{Radiological Comment}

Postero-anterior X-rays of the chest in an " early " case of calcified aortic valve show no evidence of cardiac enlargement: the only change observed is "rounding" of the left lower border of the heart, indicating left ventricular hypertrophy (Fig. 1). The aortic shadow is normal, but a slowly expanding pulsation of the aorta may be seen on the fluorescent screen. In the later stages of the disease, left ventricular enlargement becomes obvious, with increased transverse diameter of the heart. 
FIG. 3.-Oblique tomogram of the heart demonstrating the shadows of calcified mitral and aortic valve. The mitral shadow is projected below the aortic one.

Radiological demonstration of the calcified aortic valve is essential for accurate diagnosis. The two methods in common use are fluorescent screen examination and localized overpenetrating X-rays of the heart in oblique positions. Intracardiac calcification was demonstrated radiologically for the first time by Klason (1931), who diagnosed a calcified annulus fibrosus on the fluorescent screen: but he failed to reproduce it on an X-ray film. Saul (1932) was the first to succeed in obtaining a permanent record of a similar case. Sosman and Wosika (1933) reported 12 cases of calcified aortic valve, and 13 cases of calcified mitral valve, in which they had observed the intracardiac calcification on the fluorescent screen. In their paper a number of important technical points are stressed, among them the need for adequate dark adaptation prior to screening, the use of minimum screen aperture, and examination in the oblique positions. Many workers have reported successful application of the technique described by Sosman and Wosika (Parade

and Kuhlman, 1933; Bishop and Roesler, 1934; Sparks and Evans, 1934; Sundberg, 1941; and Odquist, 1944).

In the present series demonstration of calcified valves by screen examination or overpenetrating radiographs was not possible in all cases. An attempt was therefore made to show the valves by tomography.

Tomography was carried out with the patient lying supine in the left posterior oblique position: the tube was centred $10 \mathrm{~cm}$. below the suprasternal notch in the midline. Three or four horizontal "sections" were taken at $1 \mathrm{~cm}$. intervals above and below an arbitrary plane, which experience has shown should be 13 to $14 \mathrm{~cm}$. above the table top: some of these X-rays inevitably include both aortic and mitral valve areas.

The anatomical position of the aortic and mitral valves in X-rays taken in the left posterior oblique position was first ascertained in the cadaver, after lead strips had been placed at the level of the aortic 


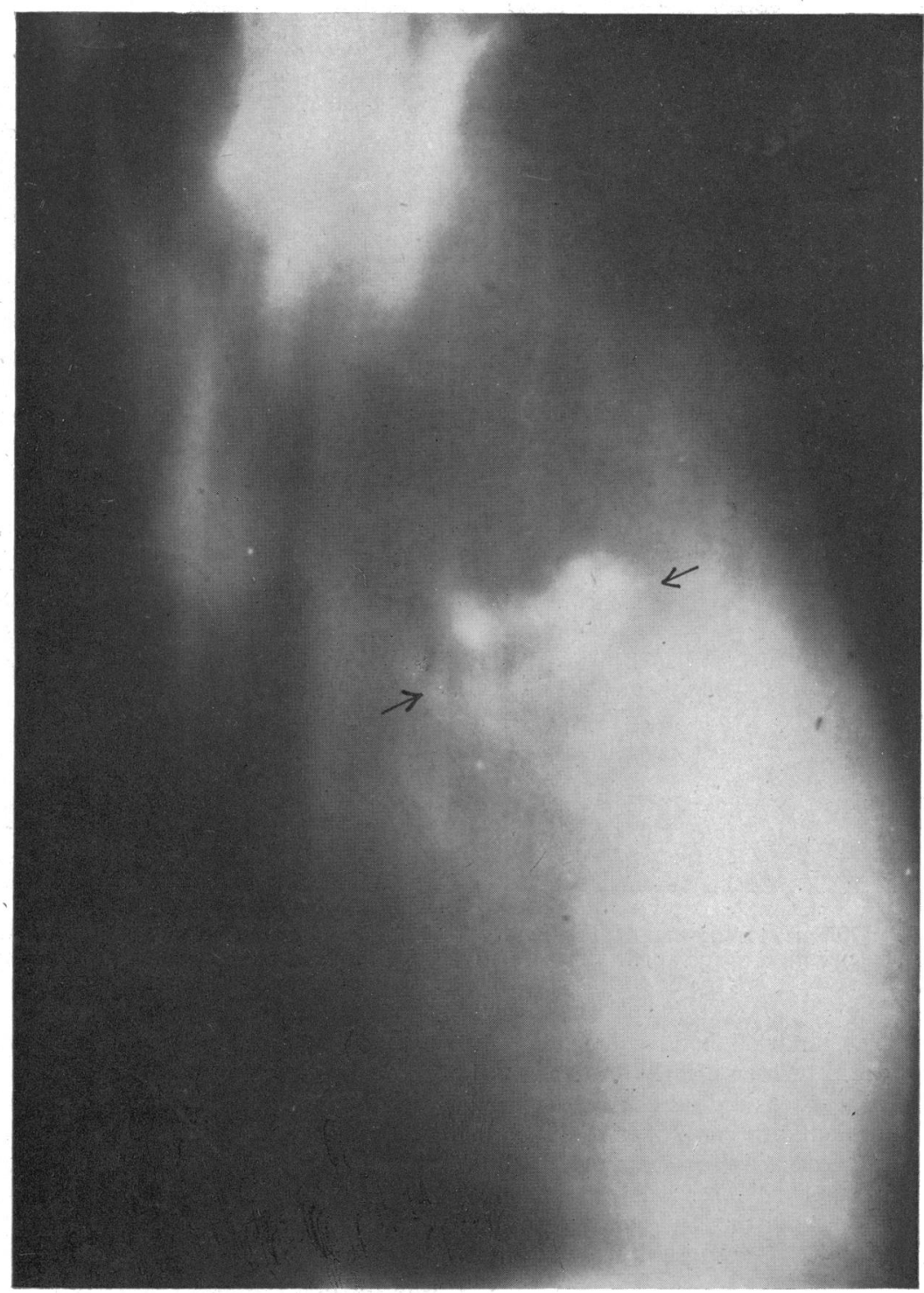

FIG. 5.-Case 3. Oblique tomogram of the heart: the calcified aortic valve is demonstrated.

and mitral cusps of a normal human heart (Fig. 2). Le-Wald (1916) used a similar method to demonstrate the position of the heart valves relative to the anterior thoracic wall.

Analysing the shadows cast by calcified heart valves in such tomograms, it is seen that the aortic valve is projected below and dorsal to the level of the pulmonary conus: the mitral valve lies below the aortic and roughly in the same plane (Fig. 3).
Slight variations in position are common, depending on the size of the heart and associated valvular lesions. Sosman (1934) has discussed these variations extensively; the findings in the present series are similar. If the aortic valve is heavily calcified a clearly defined shadow giving the appearance of a ring is seen (Fig. 4 and 5). In other cases more vaguely outlined shadows are found in the valve area (Fig. 6 and 7). 


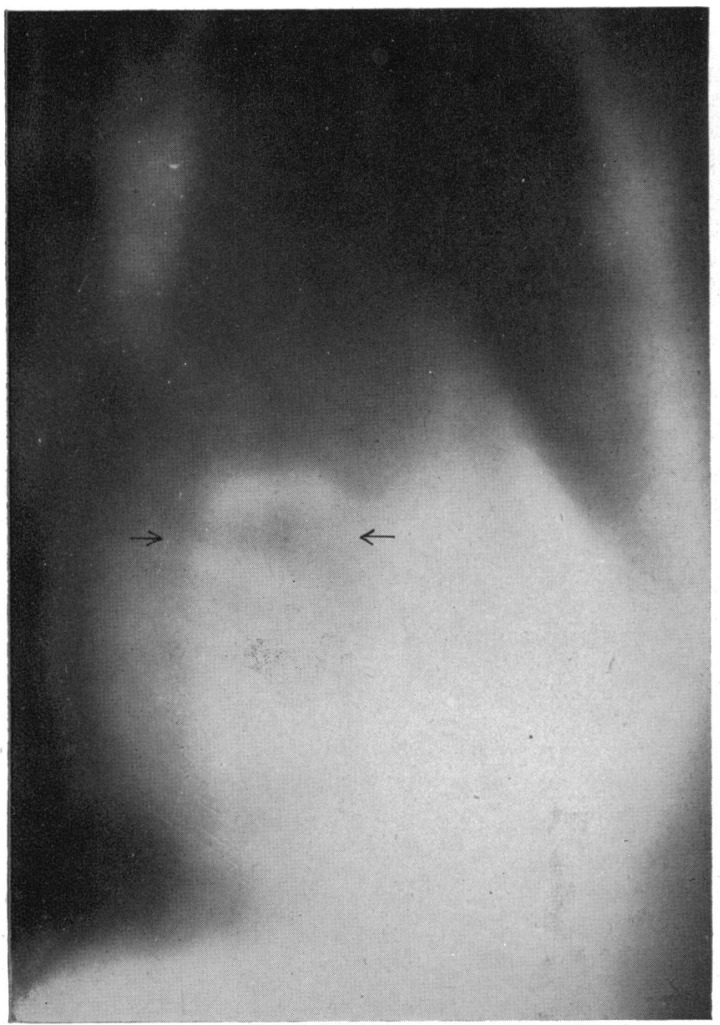

FIG. 6.-Case 11. Oblique tomogram of the heart demonstrating calcification of the aortic valve.

In 6 of the cases reported here, calcification of the aortic valve could be seen clearly on the fluorescent screen: in 3 there was a doubtful shadow that could not be identified with certainty: in the other 5 cases screening failed to show any evidence of calcified valves. In only 4 cases was reproduction of the calcified shadow on an overpenetrating oblique X-ray possible. Tomography showed the lesion in all 14 cases.

It appears, therefore, that tomography is the best method at present available for demonstrating and recording intracardiac calcification.

\section{Prognosis}

Allbutt (1898) states: "Aortic stenosis is a long disease, for life may continue under favourable circumstances until the aperture is reduced to the size of a crow-quill or less." That point of view still holds today (Scherf, 1938).

The prognosis varies with the age of the patient, and the presence or absence of symptoms at the

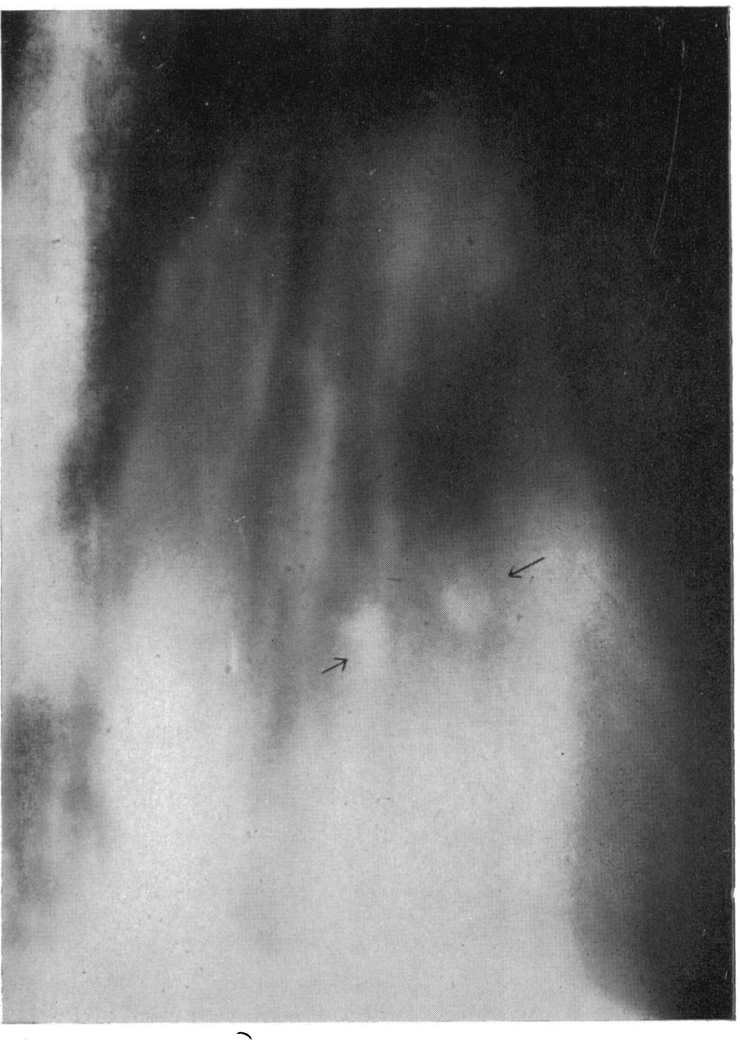

FIG. 7.-Case 2. Oblique tomogram of the heart demonstrating calcification of the aortic valve. Two separate areas of calcification cán be seen.

time of diagnosis. If discovered in a fairly young person without symptoms, the prognosis is good, the average age at death being 52 (Contratto, 1940). If, however, the patient is first seen with symptoms, the prognosis is poor, the average expectation of life in the presence of congestive cardiac failure being 9 months (Contratto, 1940); of dyspnœa, 23 months; and of syncope, 9 months (Contratto and Levine, 1937).

In the present series 4 out of 14 are known to be dead. Case 2 died within 6 months of the first attack of syncope, and within 18 months of the onset of angina at the age of 62 . Case 4 died at the age of 58, having been known to have a heart murmur for 30 years, and with 5 years history of dyspnœa, and 3 years history of angina. Case 6 died at the age of 60 , after one year's mild angina and dyspnœa: he had had acute rheumatism 40 years previously. Case 7 died, aged 35, after 6 months dyspnœa of effort, and œdema of the ankles for two days.

Causes of death. A certain number of cases die 
from causes not connected with the cardiovascular system (as many as 40 per cent in the series of Reich, 1945).

Congestive cardiac failure. Congestive cardiac failure is the commonest cause of death: it is responsible for about 35 per cent of deaths in the series reported by Grant (1933), by Reich (1945) and by Contratto and Levine (1937). In contrast to mitral stenosis, where the patient may survive several attacks of congestive failure, a patient with failure due to calcified aortic valve rarely recovers (Contratto, 1940). One patient (Case 7) in the present series died of congestive failure after a very short illness.

Sudden death. After congestive cardiac failure, sudden, unexpected death is the commonest termination. It is of interest that the first case recorded (Bonet, 1697) describes sudden death in a Parisian tailor who was apparently in excellent health. Many other similar cases have been reported (Lloyd, 1846; Gautier, 1840; Trousseau, 1870; Wilks and Moxon, 1898; Grant, 1933; Lutembacher, 1921). The incidence of sudden death is variably estimated, the average figure being about 18 per cent, although in some series it is very much lower (Campbell and Shackle, 1933), and in others very much higher, as in the selected material of Marvin and Sullivan (1935). In the present series, of the four patients who have died in a two year follow-up, three died suddenly.

The features and cause of sudden death have been carefully studied by Marvin and Sullivan (1935). They find that death occurs in seconds rather than in minutes, resembling death from coronary thrombosis: but no disease of the coronary arteries is usually found at autopsy. Nor is the sudden death related to the degree of aortic stenosis. They suggest a relation to heart size, pointing out the relative ease with which ventricular fibrillation is induced in large hearts. The relation between syncopal attacks and sudden death is not constant, but is sufficiently frequent to suggest that both are due to a sudden reduction in coronary blood flow with low cardiac output. De Veer's suggestion (1938) that sudden death may be due to "locking of the cusps with complete occlusion of the aortic orifice " is quite unconvincing.

But, whatever the mechanism, sudden death is a frequent event in cases of calcified aortic valve, even though they are symptom-free, and therefore necessitates a guarded prognosis.

Other causes of death. A few patients have died of superadded subacute bacterial endocarditis (Contratto and Levine, 1937) and a few of coronary thrombosis (Boas, 1935).

\section{SUMMARY}

The clinical and radiological features of 14 cases of calcified aortic valve are described, with a method of demonstrating the valves by cardiac tomography.

Twelve of the 14 cases were men, 2 were women. Their ages ranged from 27 to 71 years, the average being about 50 years. Four gave a history of acute rheumatism in the past.

The symptoms complained of were dyspnœa, angina, syncope, œdema, and loss of memory, in that order of frequency. Four patients had no cardiovascular symptoms.

The only constant physical finding was a basal systolic murmur propagated to the root of the neck; other findings were absence of the second aortic sound (11 cases), an aortic systolic thrill (9 cases), an aortic diastolic murmur (6 cases), cardiac enlargement ( 8 cases), and low pulse pressure ( 7 cases).

The electrocardiograms of 3 of the patients were normal: 11 showed left axis deviation, and of these one showed left bundle branch block, one $2: 1 \mathrm{~A}-\mathrm{V}$ block, and one anterior coronary insufficiency.

Four of the 14 patients are known to be dead in a two-year follow up: three died suddenly and one in congestive cardiac failure.

Tomography was found to be a more successful method of demonstrating calcified valves than screen examination or overpenetrating oblique $\mathrm{X}$-rays.

\section{REFERENCES}

\section{Clinical}

Allbutt, T. C. (1898). A System of Medicine. The Macmillan Co., London. 5, 907.

Baker, L. A., Sprague, H. B., and White, P. D. (1943). Amer. J. med. Sci., 206, 31.

Baker, J. P., and Weiss, S. (1933). Medicine, Baltimore. 12, 297.
Bennett, W. H. (1930). Brit. med. J., 1, 948.

Berk, L. H., and Dinnerstein, M. (1938). Arch. intern. Med., 61, 781.

Blackford, M., and Bryan, R. (1936). J. Amer. med. Ass., 107, 781.

Boas, E. P. (1935). Amer. J. med. Sci., 190, 376.

Bonet, T. (1700). Quoted from White, P. D. (1946) Heart Disease. Macmillan \& Co., N.Y. p. 627. 
Bramwell, C., and King, J. T. (1942). Principles and Practice of Cardiology. Oxford University Press. London.

Cabot, R. C. (1926). Facts on the Heart. W. B. Saunders \& Co. Philadelphia. pp. 205-252 and p. 767.

Campbell, M. (1937). British Encyclopæedia of Medical Practice. Butterworth \& Co. London. Vol. VI. p. 329.

__ and Shackle, J. W. (1932). Brit. med. J., 1, 328.

Chevers, N. (1842). Guy's Hospital Reports, 7, 387.

Christian, H. A. (1931). J. Amer. med. Ass., 97, 158.

Clark, J. H. (1931-2). Med. Clin. N. Amer., 15, 473.

Clawson, B. J., Bell, E. T., and Hartzell, T. B. (1926). Amer. J. Path., 2, 193.

—, Nobel, J. F., and Lufkin, N. H. (1938). Amer. Heart J., 15, 58 .

Cohen, L., Gray, I., Nash, P. I., and Fink, H. (1940). Ann. intern. Med., 13, 2091.

Contratto, A. W., and Levine, S. A. (1937). Ibid., $10,1636$.

- (1940). Med. Clin. N. Amer., 24, 1365.

Cowper, W. (1706). Phil. Transactions. London. 24, 1970.

De Veer, J. A. (1938). Amer. Heart J., 15, 243.

Dry, T. J., and Willius, F. A. (1939). Ibid., 17, 138.

East, T. (1932). Proc. Assn. Phys. Great Britain and Ireland. Quart. J. Med., 15, 693.

Fothergill, J. (1879). The Heart and its Diseases. J. Millner. p. 162.

Friedberg, D. K., and Sohval, A. R. (1939). Amer. Heart $J ., 17,452$.

Friedwald, W. F., and Ewing, A. R. (1938). Amer. J. med. Sci., 196, 400 .

Gautier, M. (1860). Gaz. Hôp. Paris, 33, 306.

Gibbs, A. J. (1935). Guy's Hospital Reports, 85, 275.

Grant, R. T. (1933). Heart, 16, 275.

Hall, E. M., and Ichioka, T. (1940). Amer. J. Path., 16, 761 .

Hasse, C. E. (1846). An Anatomical Description of the Organs of Respiration and Circulation. (Translated by W. E. Swaine.) London, New Sydenham Soc., p. 134.

Karsner, H. T., and Koletsky, S. (1940). Trans. Ass. Amer. Phys., 55, 188.

-_, - (1947). Calcified Diseases of the Aortic Valves: Lippincott.

Lannaec, R. T. H. (1829). Diseases of the Chest. (Translated by Dr. Forbes.) Thos. and George Underwood. Ch. XVIII. p. 643.

Levine, S. A. (1945). Clinical Heart Disease. W. B. Saunders \& Co. Philadelphia. Pp. 47-53.

Lewis, T. (1934). Diseases of the Heart. Macmillan \& Co. London.

Libman, E. (1913). Amer. J. med. Sci., 146, 625.
Lloyd. (1846). Trans. path. Soc., London. 1, 67.

Lutembacher, R. (1921). Pr. med., 21, 203.

Margolis, H. M., Ziellessen, F. O., and Barnes, A. R. (1931). Amer. Heart J., 6, 349.

Marvin, H. M., and Sullivan, A. G. (1935). Ibid., $10,705$.

McGinn, S., and White, P. D. (1934). Amer. J. med. Sci., $188,1$.

Monckeberg, J. G. (1904). Virch. Arch.'f. Pathol. Anat. Physiol. Klin. Med., 176, 472.

Morgagni, G. B. (1769). Quoted from Major, R. H. (1939) Classic Descriptions of Disease. Second edition. Springfield, U.S.A. p. 377.

Parkes-Weber, F. (1897). Trans. clin. Soc., London. 30, 224.

Peacock, T. B. (1868). Trans. path. Soc., London, 19, 163

Perry, C. B. (1936). Bacterial Endocarditis. John Wright \& Sons. Bristol. p. 2.

Reich, L. (1945). Ann. intern. Med., 22, 234.

Scherf, D. (1938). Klinik und Therapie der Herzkrankheiten und der Gefasserkrankungen. Julius Springer. Wien. pp. 95-100.

Smith, H. L. (1931). Med. Clin. N. Amer., 15, 217.

Sohval, A. R., and Gross, L. (1936). Arch. Path., $22,477$.

Sophian, L. H. (1945). Amer. J. med. Sci., 210, 644.

Thalheimer, W. (1922). Arch. intern. Med., 30, 321.

Trousseau, A. (1870). Clinical Medicine. The New Sydenham Soc. Vol. III. p. 399.

Vieussens, R. (1715). Quoted from Major, R. H. (1939) Classic Descriptions of Disease. Second edition. Springfield, U.S.A. p. 375.

Wilks, S., and Moxon, W. (1889). Lectures on Pathological Anatomy. J. \& A. Churchill. London. p. 139.

\section{RADIOLOGICAL}

Bishop, P., and Roesler, H. (1934). Amer. J. Roentgen., 31, 1.

Klason, T. (1931). Acta Radiologica, 1, 161.

Le-Wald, L. T., and Senior, K. D. (1916). Amer. Atlas Stereoroentgenol, 2, 37.

Odquist, H. (1944). Acta Radiologica, 25, 686.

Parade, G. W., and Kuhlmann, F. (1933). Munch. Med. Wochschr, 1, 99.

Saul, W. (1932). Fortschr. a. d. G. d. Roentgenstrahlen, 46, 450.

Sosman, M. C., and Wosika, P. H. (1933). Amer. J. Roentgenol., 30, 328.

- - (1934). Amer. Heart J., 10, 156.

Sparks, J. V., and Evans, C. (1934a). Brit. med. J., $1,1028$.

(1934b). Brit. J. Radiol., 7, 463.

Sundberg, C. J. (1941). Acta Radiologica, 22, 834. 